\title{
Experiences of Mentoring in the UK Hospitality Sector
}

Ms. Stefanie Eissner BA, MSc - Sales Manager - London Cluster Edwardian Hotels, London, UK. Email stefanie.eissner@web.de

Dr Judie Gannon*, BA, MA, FIH, MCIPD PgCert - Senior lecturer HRM (Coaching \& Mentoring) Business \& Management, Business School, Oxford Brookes University, Faculty of Business, Oxford OX3 1BP, UK. Email jmgannon@brookes.ac.uk

*Corresponding author, 


\section{Experiences of Mentoring in the UK Hospitality Sector}

\section{Abstract}

The challenges of developing and managing the future generation of hospitality employees and managers has highlighted the value of using mentoring to effectively socialize, support and nurture human resources (Gannon \& Maher, 2012; Chew \& Wong, 2008; Ayres, 2006). This study examines the experiences of mentors and mentees in the UK hospitality industry using interviews and focus groups. Findings expose the beneficial outcomes of mentoring as well as the forms it can take but also the issues which may arise from this developmental intervention. The value of mentoring is highlighted, in an industry facing significant human resource dilemmas, due to its capacity to enhance the industry's image alongside its typical career development and psychosocial functions.

\section{Introduction}

With around 70 percent of listed Fortune 500 companies reporting the use of formal mentoring programmes (Gutner, 2009) and recognition of the wider benefits of this developmental intervention (Ibarra et al., 2010; Meister \& Willyerd, 2010) many hospitality organisations have adopted mentoring in recent decades (Kim, Im \& Hwang, 2015; Gannon \& Maher, 2012; Simmonds \& Zammit Lupi, 2010; Chew \& Wong, 2008). Exploring the merits of mentoring schemes is important where companies need to manage the skills and knowledge gap, are dealing with increasingly diverse workforces, need to maximise the resources devoted to developing their people and individuals themselves, and are keen to understand the virtues of engaging as mentors and mentees (Ayres, 2006; Megginson et al., 2006; Garvey et al., 2014). This study focuses upon mentoring in the UK hospitality sector adopting Ragins and Kram's (2007, p. 5) definition of a mentoring relationship as a "developmental relationship that is embedded within the career context" as its foundation. In an industry reproached for high levels of labour turnover, stressful work environments, 
diverse and transient workforces, poor perceptions of career development and human resource management (HRM) practices (Lee, 2016; Kim et al., 2015; Davidson, McPhail \& Barry, 2011; Chew \& Wong, 2008; Ayres, 2006) mentoring may appear to be a critical developmental intervention for individuals and organizations.

The purpose of this article is to examine the experiences of mentors and mentees in the UK hospitality industry and the following objectives structure this investigation;

1. Explore the experiences of mentors and mentees participating in mentoring schemes in the hospitality sector.

2. Evaluate the opportunities mentoring presents for individuals, organisations and the wider industry

3. Offer insights for company executives and managers on how to sustain mentoring as a developmental intervention in the hospitality sector.

\section{Literature Review}

Mentoring sits alongside coaching as a developmental relationship which facilitates the growth of its participants (Rock \& Garavan, 2006). The term "mentor" is generally used, in a much narrower sense, to mean teacher, advisor or sponsor (Garvey et al., 2014) whose initial function is to teach and transfer. However, evidence suggests the benefits of mentoring are widespread and can reach across different stakeholders (Garvey et al., 2014; Wang et al., 2008) though research has mainly focused on the advantages experienced by mentees (Grima et al., 2014). At the personal level benefits include; "behavioural, attitudinal, health-related, relational, motivational [benefits], and career outcomes" (Eby et al., 2009, p.254). Kram's (1985) early work categorised the benefits of mentoring broadly as falling into two camps; vocational or career and psychosocial. Career focused (vocational) benefits are a reference to "the relationship that enhances career advancement" due to the influence and rank a mentor has within an organisation (Kram, 1985 p.23) while psychosocial refers to the development 
of confidence, competence, friendship, recognition and personal validation (Zagenczyk et al., 2009).

Organisational and other stakeholder benefits include knowledge and experience transfer where mentoring is a highly cost efficient development method for future talent within a company (Hu, Wang, Yang \& Wu, 2014; Simmonds \& Zammit Lupi, 2010; Parise \& Forret, 2008). Furthermore by facilitating a mentoring culture benefits such as, higher performance and productivity are typically accrued (Klasen \& Clutterbuck, 2012). Mentoring is also associated with better socialisation outcomes within organisations (Baugh \& Fagenson-Eland, 2007; Chao. 2007). In addition, mentors gain from the mentoring relationship, through reflection and improvements in their leadership skills as part of this developmental relationship (Rekha \& Ganesh, 2012; Parise \& Forret, 2008). There is also a strong correlation between those who have been mentored and those who are keen to mentor themselves, giving back, advising and guiding others, reciprocating their own experiences (Rekha \& Ganesh, 2012). By building rapport and trust with mentees mentors also often improve their own developmental and promotion opportunities (Grima et al., 2014; Rekha \& Ganesh, 2012).

\section{Mentoring in Organisational and Industrial Contexts}

Structured organisational mentoring schemes became popular for the first time in the 70's (Zachary, 2005; Garvey et al., 2014) as one of the primary learning strategies used by HRM departments. Typically mentoring interventions are used with new employees/graduates, line managers, as well as for senior level managers or board directors due to their value in supporting transitions and socialising individuals (Chao, 2007; Young, Cady \& Foxon, 2006). Research has shown that mentoring programmes exist in a variety of industries, which equally benefit from these developmental relationships (Garvey et al., 2014) as it is particularly useful for "building organizational intelligence [...] connecting across people [...] (and) sustaining business impact" (Murrell et al., 2009 p. 2). 
The literature highlights that mentoring occurs informally as well as being formally instigated by organisations (Megginson et al., 2006; Garvey et al., 2014; Rutti, Helms \& Rose, 2013). Formal mentoring offers the highest level of control and influence of the development of the participants and can assist an organisation's attempts to address issues of equality and diversity (Rutti et al., 2013; Parise \& Forret, 2008; Chao, 2007). Formal settings tend to be more goal-focused which means specific objectives are set and the relationships have a clear direction with specific expectations of the mentor and mentee clarified (Garvey et al., 2014; Ragins \& Cotton, 1999). Trained mentors in formal relationships can act more effectively as they are aware of the benefits and want to demonstrate their commitment to the organisation and the development of future talent (Garvey et al., 2014; Parise \& Forret, 2008; Megginson et al., 2006). Typically formal mentoring schemes pursue organisational goals rather than individual ones and include precise plans about the frequency and the type of contact (faceto-face or online) (Parise \& Forret, 2008; Inzer \& Crawford, 2005).

While the majority of the literature identifies mentoring as a beneficial activity there is also evidence of mentoring having adverse effects on participants and organisations (Eby, Butts, Durley \& Ragins, 2010; Parise \& Forret, 2008). Like any other human relationship factors associated with the individuals concerned, the coordination of their relationship and other organisational and situational factors can create a toxic encounter, however, few authors have studied this area though it is acknowledged more widely in the practitioner literature (Parise \& Forret, 2008; Megginson et al, 2006).

\section{Forms of mentoring}

Traditional mentor-mentee relationships have developed into various organisational mentoring processes (Meister \& Willyerd, 2010; Zachary, 2005). Eight broad types of mentoring are evident in the literature; one to one, group, team, peer, new-hire, highachiever, executive, online and reverse (D’Abate, Eddy \& Tannenbaum, 2003). One-to-one mentoring focuses on a dyadic relationship based on the connection and the trust developed 
between mentor and mentee, while team mentoring concentrates on mentoring to support the dynamics of teams while also addressing individual mentee growth. Peer mentoring abandons the principle of one participant having expertise and the other benefitting from that knowledge and experience to focusing on both participants being equally resourceful and sharing the mentor and mentee roles. New-hire mentoring or buddying systems are used to socialise new colleagues and understand the culture and structures within a company (Chao, 2007; D’Abate et al., 2003). High-achiever mentoring has emerged as a result of talent management where high potential individuals are targeted with developmental interventions and executive roles to facilitate their growth (Cooke, Saini \& Wang, 2014; Joo et al., 2012). Likewise executive mentoring highlights the attention which senior human resources are afforded given their strategic roles within organisations (Harvey, McIntyre, Thompson Hearmes \& Moeller, 2009). Online, distance or e-mentoring has emerged as a means for geographically dispersed organisations to deploy mentoring and is facilitated by communication technologies such as email, telephone, instant messaging, electronic learning platforms, forums, video conferences etc. (Simmonds \& Zammit Lupi, 2010; Garvey et al., 2014). Online mentoring schemes are often less intense and building a successful relationship often takes more time and persistence. Moreover not all mentors are suitable for this kind of relationship as it requires an affinity for technology (Garvey et al., 2014; Megginson et al., 2006).

Finally, reverse mentoring, which may also be known as upward mentoring provides a contrast to traditional mentoring as a less experienced, often younger person, in a junior position is in the mentor role (Murphy, 2012; Garvey et al., 2014). This form of mentoring is particularly valuable where more experienced human resources are challenged by developing technology trends or changing customer needs as it provides an opportunity to connect and stay informed about significant developments (Murphy, 2012; Garvey et al., 2014). Reverse mentoring has also been used to foster diversity awareness and therefore supports the 
understanding and promotion of women and other minority groups (Murphy, 2012; Young et al., 2006).

\section{Mentoring in the Hospitality Industry}

The hospitality industry is known to face many people management challenges being labelled a high labour turnover, low-skill, low-paid sector, it is also associated with unsociable hours, pressurised operational and managerial roles, diverse and transient workforces (Kim et al., 2015; Lee, 2016; Davidson et al., 2011; Kusluvan, Kusluvan, Ilhan \& Buyruk, 2010). Amidst these wider industry human resources challenges is the evidence that the proportion of young people entering the workforce is set to decline due to demographic shifts in the population (People 1st, 2015). Simultaneously many authors highlight the dilemmas the industry faces in meeting the demand for managerial and operative human resources as it grows and emerging generations question the value of developing their careers in the sector (Kong, Wang \& Fu, 2015; Brown, Thomas, \& Bosselman, 2015). Studies on mentoring studies in the hospitality and related industries have covered a relatively focused set of areas. Early work by Rutherford (1984), Rutherford \& Wiegenstein (1985) and Lankau and Chug (1998) identified the career and mental health benefits of mentoring in the hotel industry. Ayres (2006) ascertained that mentoring was valuable alongside mobility for developing successful careers in the wider leisure and tourism industries, while Chew \& Wong (2008) explored how career mentoring can retain staff and enhance organisational commitment. Gannon \& Maher (2012) investigated the role of mentoring in supporting hospitality graduates' transitions into the industry assisted by hospitality executives as mentors and Kim et al (2015) found that mentoring supported hospitality employees through issues of role stress, job attitude and turnover intention. As mentoring appears to offer a myriad of forms and possible benefits for individuals, organisations and sectors, in terms of fostering personal and career development and enhancing organisational outcomes, studying the experiences of mentors and mentees 
offers potentially insights into how this development intervention might influence the overall image of the hospitality and support the attraction and retention of future talent.

\section{Methodology}

The exploratory nature of this study of mentoring in the hospitality industry led to the adoption of a qualitative approach to allow a variety of stakeholders to explain their experiences of and insights on mentoring (Bryman \& Bell, 2011). Using semi-structured interviews and focus groups allowed the researchers' access to the phenomena of mentoring through the mentors' and the mentees' recounts.

\section{Research Participants}

Mentors were recruited through contacting the authors' own personal networks and then extended further via the snowball sampling technique (Bryman \& Bell, 2011). However, due to the challenges of accessing mentees from in-company mentoring schemes in the hospitality industry the researchers sought an alternative pool of mentee participants. They gained access via a mentoring scheme for degree students in hospitality management studying in the UK. The preselected attributes for all participants included experience as a mentor/mentee in the hospitality industry. All the mentors recruited were senior executives in different hospitality organisations (including hotel companies, food service management and HR consultancies) with extensive, typically more than ten years of mentoring experience. Due to issues concerning the availability of mentors and mentees the researchers conducted ten face-to-face interviews with mentors and used six focus groups with twenty mentees, in groups of three to four members.

\section{Instrument and Data collection}

Semi-structured interviews were used due to their suitability to gather rich qualitative data (Bryman \& Bell, 2011) and an interview guide was developed based on the mentoring literature. Interview questions were piloted with an industry contact who did not participate in the study. The questions for the mentors focused upon their own backgrounds and careers, 
their mentoring experiences as mentees and mentors and how mentoring was approached in their own organisation and across the industry (Ayres, 2006; Simmonds \& Zammit Lupi, 2010). There were twelve core questions used in these interviews, with additional prompts and follow-ups used to gain greater clarity and detail.

Students involved in an industry mentoring scheme, available to those on hospitality management courses in the UK, were invited to participate in the mentee focus groups. The researchers made use of the informal study environment to conduct their focus groups and to build rapport with the participants (Bryman \& Bell, 2011). At the beginning of each session the aim of the research was introduced to the participants who were then led through a series of questions and prompts to capture their views and experiences of mentoring. In all there were six main questions asked in the focus groups which centred on the participants' background details and their experiences of mentoring during their programme, work experiences and careers to date, and their wider views of mentoring in the industry. The duration of the six focus groups was just over one hour and all sessions were recorded. The researchers' field-notes were used to develop descriptive narratives shortly after completion of the sessions.

\section{Data analysis}

Data analysis involved transcribing the interviews and focus groups, and re-reading the fieldnotes and transcriptions to develop an in-depth understanding of participants' experiences to capture the "richness of real social experience" (Schutt, 2012, p. 322). As with most qualitative studies data reduction was a key challenge, however, two main categories within the data emerged; comments regarding the benefits and challenges of mentoring and comments about the forms of mentoring experienced (Patton, 2002). Further coding then helped sub-themes surface within these two main clusters, breaking up and sorting and comparing the data across the focus groups and mentor interviews. 
The trustworthiness and authenticity of this qualitative study were addressed using (Shenton, 2004) the four criteria of credibility, transferability, dependability, confirmability and authenticity. In terms of credibility and dependability this study involved 'early familiarity' with relevant organisational settings, triangulation through the use of interviews as well as focus groups and confirmation of transcriptions with participants. Transferability was addressed through the recruitment of mentors from across organisations and sectors of the hospitality industry in the UK, whereas confirmability was pursued through attempts to capture negative as well as positive experiences of mentoring in the focus groups and interviews. Authenticity was observed through the attempts to capture both mentors' and mentees' experiences of mentoring within the hospitality industry and by drawing on their experiences of different schemes across a variety of hospitality organisations.

\section{Findings and Discussion}

The findings are presented using the two main clusters of; the benefits and limitations of mentoring and the approaches to mentoring experienced by the respondents. It is, however, worth reflecting upon key characteristics of the mentees and mentors who participated in this study. Three generational groups are evident across the sample: Generation Y (1981-2000) broadly represented by the mentees, and Generation X (1965-1980) and the Baby Boomers (1946-1964) evident in the mentor group. All the mentors had worked in the hospitality industry for between 10 and 40 years and had personally experienced informal and formal mentoring relationships. There was limited cultural diversity across the participating mentors and there was an even gender split. The majority (75\%) of participating mentees were between the ages of 23 to 27 years, $65 \%$ were female and represented a culturally diverse cohort with $45 \%$ from Europe, $25 \%$ who identified themselves as Asian, a further $15 \%$ who were Indian nationals and 15\% from North America. Nearly half of the mentee group had experienced mentoring in a job-related environment and the remainder only had experience of the student-industry mentoring programme. The level of work experience amongst the 
mentees varied considerably from one to twenty years; however, the average length of work experience was nearer five years. These findings reinforce the claims in the literature that the workforce in the hospitality industry is increasing in diversity, specifically in relation to gender, generational aspects and culture (Ayres, 2006; Chew \& Wong, 2008) supporting the challenges identified in the literature.

\section{The Benefits and Limitations of Mentoring}

The mentors interviewed highlighted the significant personal benefits of engaging with mentees and the development of their mentor-mentee relationships. Mentors' views adhered to the traditional one-way relationship view where the mentor (the more experienced person) shares their ideas/experience/knowledge with the mentee (the less experienced person). The mentors identified a variety of personal outcomes they had experienced as part of their mentoring roles as identified in Table I. Particularly evident was all participating mentors' interest in working with, and acknowledging the current issues of, the next generation of hospitality managers. These issues included concerns about the challenges they face, their attitude towards work, and their interests and mind-sets as these were crucial to developing an understanding of these mentees' future careers in the hospitality industry. As one mentor commented "Well I learn a lot from mentees as well, you know. They tell me about situations that they deal with every day, so it's very educational for me to learn about challenges that they face.' (Mentor B).

Beyond their personal interests and the benefits of mentoring the mentors were also keen to recognise the value of mentoring to their organisations. In particular they were conscious of the issues of attracting and retaining the right quantity and quality of young professionals into their businesses. Mentoring was felt to be a useful tool in the battle against high levels of labour turnover and could be used as part of a retention strategy for groups of employees who had attractive and transferable skills sets. The mentors also recognised that having a 'senior' 
friend in the organisation supported commitment, engagement and motivation amongst staff. Mentor D's comments capture those of his peers, “Mentoring, it's good for retention, creates people motivation, to retain talent and develop a pipeline for future GMs, to attract people, to deliver commitment. I think to develop talent has various business advantages as it helps driving results and revenue. The same that counts for us as a company the same is true for the industry."

Table I. Mentors' views of the Benefits of Mentoring

\begin{tabular}{|c|c|c|}
\hline Per & any benefits & ry benefits \\
\hline $\begin{array}{l}\text { - Getting to know the next } \\
\text { generation } \\
\text { - Satisfaction and the feel } \\
\text { good factor of giving } \\
\text { back } \\
\text { - Getting to know new } \\
\text { people and raising their } \\
\text { expectations } \\
\text { - Sharing their skills } \\
\text { (technology, leadership, } \\
\text { trends, teaching } \\
\text { methods) } \\
\text { - Cultural awareness } \\
\text { enhancement }\end{array}$ & $\begin{array}{l}\text { - Retention/reduce labour } \\
\text { turnover } \\
\text { - } \text { Creates commitment/ } \\
\text { engagement/motivation } \\
\text { - } \text { Attract talent/source for } \\
\text { recruiting } \\
\text { - Develop talent/ increase } \\
\text { learning } \\
\text { - Transfer skills/ } \\
\text { knowledge } \\
\text { - Give back/dedication to } \\
\text { learning and } \\
\text { development }\end{array}$ & $\begin{array}{l}\text { - } \text { Transfer \& exchange of } \\
\text { knowledge } \\
\text { - } \text { Networking } \\
\text { - } \text { Highlights trends \& } \\
\text { developments } \\
\text { - Attracting people \& } \\
\text { developing talent } \\
\text { pipeline } \\
\text { - Retains talent } \\
\text { - Enhances motivation/ } \\
\text { commitment } \\
\text { - Enhancing the image of } \\
\text { the industry }\end{array}$ \\
\hline
\end{tabular}

Changing demographics, in particular, the impending retirement of the baby boomer generation heightened the need for better identification of new talent and mentoring reinforced the development of younger high-potential employees (People $\left.1^{\text {st }}, 2015\right)$. Mentors also mentioned the value of mentoring beyond their own organisations and included benefits experienced by the entire hospitality industry. Mentoring was highlighted as offering important networking possibilities, faster promotion and career progress, which aided the wider industry. Mentors commented that mentoring enhanced motivation and commitment, and as a result the image of the whole industry as an area where development and growth were available. The knowledge exchange aspect of mentoring also stood out for the mentor participants who described opportunities for information exchange within their relationships. Their younger mentees were characterised as more proficient in future industry trends, IT and 
communication technologies and therefore elements of reverse mentoring were evident as mentors were updated on these areas of knowledge by their mentees (Murphy, 2012). These findings very much reinforce the existing mentoring literature and capture clearly mentors' perceptions of the benefits of mentoring across the three dimensions of personal, organisational and industry (Grima et al., 2014; Hu et al., 2014; Rutti et al., 2013; Simmonds \& Zammit Lupi, 2010).

For the mentees, again a range of benefits accrued from their mentoring experiences. For example, benefits such as; the opportunity for self-reflection, the chance to identify personal values in a work environment, consideration of mentees achievements and the chance to build a personal career network were identified. One mentee commented "I learned that it is super important to maintain contacts with people because you never know what happens and they might bring you a new contact tomorrow or offer you an amazing opportunity." (Mentee N). Table II pinpoints the most frequently mentioned benefits of mentoring as suggested by mentees across the six focus groups.

\section{Table II. Mentees views of the Benefits of Mentoring}

\begin{tabular}{|c|c|}
\hline Personal benefits & Industry benefits \\
\hline $\begin{array}{l}\text { - To gain practical experiences } \\
\text { (internship, work experience) } \\
\text { - Feedback on their CV } \\
\text { - Enhanced confidence and } \\
\text { encouragement } \\
\text { - Support on how to deal with negative } \\
\text { feedback or difficult situations } \\
\text { - Networking and the building of } \\
\text { contacts }\end{array}$ & 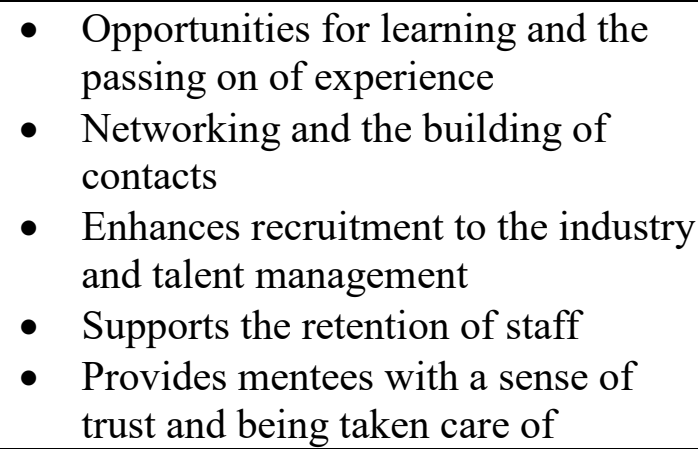 \\
\hline
\end{tabular}

The first two benefits in Table II were based on students' experiences of the universityindustry mentoring scheme, whereas the other benefits were mentioned as part of experiences of both university-industry and in-company mentoring programmes. Mentees were also keen to recognise that the benefits of mentoring stretched past their own personal experiences and 
the second column of Table II captures these features. For example, the opportunities for building on an experienced executive's experiences and being offered access to their network are captured by Mentee A who remarked "I think in some ways it can reduce the generation gaps, to maybe respect the elderlies a bit more." The benefits of mentoring to the industry are remarkably similar between both the mentor and mentees groups with learning and knowledge transfer being highlighted, as well as network building and the possibility of enhancements to key HRM challenges identified within the industry (Zagenczyk et al., 2009; Murrell et al., 2009; Ayres, 2006). It appears that for an industry which can be extremely hierarchical mentoring offers an opportunity to connect senior managers and future managers and employees, which are not apparent in other career development interventions (Kim et al., 2015; Ayres, 2006).

While both mentors and mentees clearly expressed the beneficial aspects of mentoring they were also able to recognise the limitations of mentoring. Both sets of participants were concerned about the sustainability of mentoring as it became more widespread in the industry. Mentors specifically felt that if companies only focused on mentoring for newentrants then other groups of employees may feel under-valued. There were also fears that the growth in mentoring might mean that unsuitable mentors, would be recruited by mentoring scheme coordinators, and that schemes may also not be able to provide adequate training for new mentors. The mentee participants likewise suggested that the increasing use of mentoring might mean that mentors would be encouraged to mentor more mentees and have less availability to focus on the development of specific individuals. Overall both mentors and mentees expressed apprehension that the increasing prevalence of mentoring might mean that the value of mentoring itself may diminish if not managed successfully (Parise \& Forret, 2008; Megginson et al., 2006). 
The participants also indicated that companies and organisations operating mentoring schemes needed to be clear about their expectations of mentors and mentees as managing the finite nature of some mentoring relationships was often complex (Eby, et al., 2010; Parise \& Forret, 2008). Similarly the development of clear guidelines was important where difficulties might emerge, in particular for those new mentors or mentees. Mentors also acknowledged that companies face difficulties in assessing the effectiveness of mentoring schemes and specifically identifying their direct impact on labour turnover rates and the transfer of knowledge and learning (Parise \& Forret, 2008; Chew \& Wong, 2008). There were also worries that corporate mentoring schemes may face difficulties with the neutrality of mentors and confidentiality issues within relationships (Parise \& Forret, 2008).

Mentees were also asked to indicate their willingness to become a mentor in the future, supporting arguments in the literature (Rekha \& Ganesh, 2012). The majority of mentees could imagine themselves acting as a mentor in the future once they had accrued more work experience. Mentee A indicated "I would like to give something back" while Mentee J was a passionate advocate, "I want to be a mentor; I am willing to help other mentees". More detailed responses are evident from Mentee $\mathrm{P}$ who argued "I would love to, because there is a lot of learning as my mentor told me" and Mentee S: "I wouldn't ever have learned that on my own, so if I can give that somebody else then yeah... Part of the whole programme is everyone is making it better for everybody else, because they remember what it was like when they started. So it's the absolute generation gap, but then with my mentor he started his career just before the economic crash, stuff moves so fast and it always gonna be beneficial to stay in touch with people who were coming up." Those mentees who were not keen to become mentors in the future described themselves as having less successful mentoring relationships, as their expectations had not been met and where little communication had taken place. 


\section{Forms of Mentoring}

Mentors preferences strongly indicated that one-to-one mentoring relationships were more widespread and valuable. Mentor B commented: "all our mentoring is always one-to-one" and likewise Mentors' H and I indicated; “one-to-one is what I prefer, always on a single basis" and "We do one-to-one mentoring; we have in general a very strong one-to-one culture in this hotel." This tallied with mentees' experiences and preferences too, and that alongside their face to face mentoring meetings contact was maintained by telephone calls and emails. Both mentors and mentees mentioned instances where mentors had more than one mentee so that there were some experiences of group or pair mentoring. These experiences, whether in the in-company or the student-industry mentoring schemes, were seen as valuable for specific events such as initial meetings or at networking and industry events where it was convenient to combine mentees (Meister \& Willyerd, 2010). Several mentor or mentee participants mentioned peer mentoring experiences which were described as short-lived mentoring for those joining an organisation and were also referred to as buddying or new-hire mentoring (Chao, 2007). While the mentors identified the benefits of their mentees supporting their learning of knowledge and skills, specifically in relation to trends and technology, no mentors or mentees cited reverse mentoring schemes.

Across all participants the focus of mentoring initiatives were seen to be targeted at newentrants who were joining the industry, a particular level of management or a company. As such recruits on management development programmes, interns or placement students as well as apprentices were highlighted by respondents and as suggested by the literature (Chao, 2007; Young, Cady \& Foxon, 2006). Mentor G highlighted in his own organisation that it was "graduates through to senior managers reporting to the board" who were involved in mentoring and seven out of the ten mentors' companies targeted new graduates or managers in their schemes. However, four of the mentors' current companies highlighted that their mentoring programmes operated for employees at every organisational level, as indicated by 
Mentor D who comments "we use (mentoring for) people development on many different levels". This was echoed by Mentor J who stated that mentoring went "right from the top, from the CEO right through to the security guys."

There was clear agreement between mentors and mentees of the benefits of face to face meetings as a way of building rapport and improving their developmental relationships. Communication via email was used to set up meetings and to clarify questions or to give feedback (for progress reports, application letters, CVs) and as a quick way to keep each other up-to-dated. Both sets of participants reported that communication often changed after a couple of months of the relationship with the initial familiarisation phase used to build trust via face to face meetings. However, once some rapport was achieved face to face interactions normally declined in frequency in favour of virtual communication through email, Skype and phone calls to facilitate time constraints and limit travel efforts.

The early use of face to face mentoring interactions followed by virtual communication can be contrasted with mentors and mentees reactions to the merits of online mentoring per se. Only a quarter of the participating mentees felt purely online would be useful, commenting "it's not necessary" or "I don't need that" or "I prefer face-to-face" and "I personally don't like it". The majority of mentors voiced deeper concerns regarding the use of online systems due to perceptions of a loss of human interaction as well as the suitability for an industry focused on a customer-facing environment. Mentor F argued "I don't think you can replace human interaction with online mentoring." While Mentor A commented "I think for a mentoring programme to be successful it's about the development of a relationship [...] I think the trust factor is critical [...] I find it difficult to understand how an online mentoring programme could bridge that." Likewise Mentor B stated "It's very hard because you want the relationship to be organic and I worry that technology might interfere with that." Further concerns over online mentoring were highlighted where mentors suggested "I spend way too 
much time staring into a laptop already; I wouldn't voluntarily sign up for more time to be logged into another system." (Mentor E) and "It strikes me as being a very lonely or dry experience. And it certainly doesn't suit my personality." (Mentor H). There were also suggestions of perceived generational differences where several mentees worried about senior mentors engaging with the use of technologies associated with online mentoring. Mentee $G$ commented "As the mentor is so busy, they wouldn't have time to access or to use it." and Mentee E suggested; “I don't think that mine (mentor) would be technologically savvy enough." Only a few mentees were supportive of online mentoring and could imagine using this approach themselves suggesting benefits such as; "It's convenient; you don't have to travel..." (Mentee P) or "I think it would be good, because with that way there would be regularity." (Mentee $\mathrm{H})$. These findings reinforce the challenges outlined in research on ementoring elsewhere (Simmonds \& Zammit Lupi, 2010).

The mentors were specifically asked about their training to fulfil their roles as mentors as part of the interviews and the importance of 'soft skills' were highlighted as being critical here. The majority of mentors valued access to written guidelines of the schemes they were involved in, offering them guidance on the "do's and don'ts" in their mentoring relationships, the expectations of mentees as well as frequently asked questions and topics that might come up in conversations with mentees. Official training courses were only adopted by four companies and often involved external trainers. The amount of time participating in mentoring training varied significantly across the schemes from three hours to up to four days. The most common approach, however, involved informal briefings of half-day or fullday sessions, which were often followed by refresher sessions on an annual basis. Mentors with previous mentoring experiences, specific expertise or in hierarchical positions often led these briefings as captured by Mentor C "I taught the board members, and then the board members will teach the people who work for them, so it just comes down the line." Several mentors, however, suggested a variety of training experiences Mentor G commented "There 
are a lot of mentors who find themselves doing that role without adequate training [...] people are asked to go into those mentoring roles, but probably don't always get any formal training." Likewise Mentor $\mathrm{H}$ added "the training that I had has frankly been minimal but I've read a bit about the subject". There was also a perception amongst some mentors that by being asked to mentor their credentials to meet the role requirements had been recognised. For example Mentor F suggested "mentoring by the very nature what it is, I guess attracts people who are capable" while Mentor $\mathrm{J}$ indicated "I suppose they considered us as a suitable maturity and intelligent". Overall there is evidence of what might be seen as good practice in mentoring with experiences of and the valuing of training and resources for mentors. However, there is also perhaps some evidence of complacency in assuming mentors already had the skills sets required and are clear about the expectations of the mentoring schemes they were involved in.

\section{Conclusions and Implications}

The characteristics of the mentors and mentees who participated in the study reinforce the arguments for the increasing diversity of hospitality workplaces, in terms of cultural backgrounds, and generations. As such mentoring provides ways for those with different backgrounds to share their experiences and skills in meaningful ways in an industry dependent on human resources. The findings also highlight the benefits of mentoring as experienced by the mentors and mentees from personal, organisational and wider industry perspectives (Zagencsyk et al., 2009; Parise \& Forret, 2008; Ayres, 2006; Kram, 1985). Aspects of working across generations, sharing skills and knowledge, developing cultural awareness were highlighted by mentors while mentees emphasised the opportunities of gaining further practical insights, developing their network and coping strategies and improving their confidence. These mentoring experiences highlight how such a developmental relationship assists in addressing the challenges of developing a successful hospitality industry career (Gannon \& Maher, 2012; Ayres, 2006). The organisational and 
industry benefits articulated clearly address some of the human resource challenges identified in the literature where participants also see mentoring as boosting knowledge transfer, retaining talent, improving commitment and motivation and enhancing industry image (Chew \& Wong, 2008; Gannon \& Maher, 2012; Kim et al., 2015). The implications for the industry include the value of investing in mentoring initiatives to tackle some of the people management issues typically experienced. This study suggests that drawing directly on managers' and executives' experiences and expertise could alleviate perennial staffing concerns. However, there are suggestions that further investment in and understanding of mentoring and alternative developmental interventions will be an important foundation for these activities. Senior executives and HRM managers will need to develop their knowledge and skills to be able to deploy mentoring in all its forms effectively. As such working with, and learning from, human resource development practitioners from other sectors deploying mentoring will be beneficial for individuals, companies and the wider sector.

The virtuous circle effect of mentoring, where previous recipients of mentoring are more likely to engage as mentors for others later in their careers, was evident in the results (Rekha \& Ganesh, 2012; Grima et al., 2014). This legacy dimension does reinforce that ensuring the efficacy of mentoring schemes and relationships is crucial for the longer term benefits of this developmental intervention in the hospitality industry. This cumulative effect of mentoring offers opportunities for industry to encourage more managers to engage in mentoring as an altruistic act, having benefitted themselves, on early in their careers. Recognising that mentoring can be toxic for both mentors and mentees will also be important and part of executives' and managers' ongoing learning about such developmental interventions. Effectively managing the negative as well as the positive outcomes of mentoring will be crucial for mentoring becoming a sustained and flourishing intervention in the hospitality industry. 
While the traditional form of one to one mentoring was predominant across participants' responses there was also wider evidence of other mixed forms of mentoring (Meister \& Willyerd, 2010; Garvey et al., 2014). Face to face mentoring was sustained through virtual mechanisms once rapport and trust has been established, and group mentoring took place where mentors used industry events to introduce several of their mentees to their wider networks. Participants also recognised mentoring being used to socialise employees into roles and organisations and mentors, specifically valued their mentees IT and communication (social media) insights and skills. There was, however, a reluctance to promote e-mentoring as a mainstay for mentoring within the industry despite the struggles many geographically dispersed or international hospitality organisations have in recruiting and developing talent (Simmonds \& Zammit Lupi, 2010; Harvey et al., 2009). It may be that the hospitality industry, with its legacy of cherishing soft skills in a service setting, will prioritise face to face mentoring primarily due to its core values as a people industry. Specific implications for the industry include the need to encourage current managers to embrace virtual forms of mentoring support to garner the benefits for those who may be considered as being digital natives. By extending their expertise in mentoring and associated technologies executives and HRM managers will be able to identify systems which are relevant to the industry and suitable for participants with different levels of IT knowledge and backgrounds.

While hospitality organisations may be turning to mentoring to tackle some of their human resource dilemmas this study does provide some cautionary warnings. Both sets of participants suggested mentoring has limitations and should not be viewed as a failsafe solution. Concerns were voiced where support for mentoring might be poor, was overused and became devalued, and where mentors were poorly resourced, selected and trained (Eby et al., 2010; Parise \& Forret, 2008). The implications here highlight that mentoring should not be seen as a panacea and its growth and use needs to be managed with care across hospitality companies and professional organisations. This will require some coordination by executives 
and managers with systems of review and evaluation put in place to ensure appropriate targeting and deployment of this intervention. It is too easy for mentoring to be seen as an answer to the many HRM challenges facing the hospitality industry as it is capable of having adverse effects too, if not implemented and managed effectively. The industry then needs to consider whether mentoring, its' variations or other developmental interventions are more suitable (for example, coaching) for specific people management dilemmas and how these practices can be delivered. In this study the evidence that training for mentoring scheme participants may be limited highlights that mentoring scheme coordinators should be identifying the importance and benefits of becoming skilled mentors and mentees. These activities can only be successfully executed where expertise in the industry is developed through training and education and then best practices are shared.

\section{Limitations and Future Research}

This study contributes to the literature on developmental interventions, specifically mentoring, in the hospitality industry, from the perspective of both mentors and mentees. It reinforces that benefits which mentors and mentees might accrue but alerts organisations and individuals to the factors which need to be in place to ensure mentoring adds value. As with all research this study has limitations. Specifically the mentees in this study were participants from an industry-education mentoring scheme in the UK rather than full-time workers in the industry. While all of the focus group participants had at least one year's work experience in the hospitality industry only half of the mentees had experienced mentoring beyond the scheme as part of their university programme. This will have shaped their views and limited their experiences of mentoring. It would be useful to use a wider sample of hospitality industry employees to ascertain broader experiences of mentoring beyond this student cohort.

As with most qualitative research the sample sizes were small and covered a range of hospitality sectors in the UK rather than focusing on one sector explicitly. It may be that specific sectors within the hospitality industry will show different preferences and demand 
for mentoring due to the specific human resource challenges they may face. Further research focusing on mentoring and other supportive relationships (coaching for example) in specific industry sectors and at different hierarchical levels appears warranted to help further understand the value of developmental and psychosocial relationships within this labour intensive industry. Due the limited research on mentoring in the hospitality sector, however, the results of this study provide at least some valuable set of insights into this intervention's role in the industry. 


\section{References}

Ayres, H. (2006). Career development in tourism and leisure: An exploratory study of the influence of mobility and mentoring. Journal of Hospitality and Tourism Management, 13(02), 113-123.

Baugh, S. G., \& Fagenson-Eland, E. A. (2007). Formal mentoring programs: A Poor Cousin to Informal Relationship? Chapter 10. The handbook of mentoring at work: Theory, research, and practice, 249- 272.

Brown, E. A., Thomas, N. J., \& Bosselman, R. H. (2015). Are they leaving or staying: A qualitative analysis of turnover issues for Generation $\mathrm{Y}$ hospitality employees with a hospitality education. International Journal of Hospitality Management, 46, 130-137.

Bryman, A., \& Bell, E. (2011). Business Research Methods 3e. Oxford University Press.

Chao, G. T. (2007). Mentoring and organizational socialization. The handbook of mentoring at work: Theory, research, and practice, 179-196.

Chew, Y. T., \& Wong, S. K. (2008). Effects of career mentoring experience and perceived organizational support on employee commitment and intentions to leave: A study among hotel workers in Malaysia. International Journal of Management, 25(4), 692

Cooke, F. L., Saini, D. S., \& Wang, J. (2014). Talent management in China and India: A comparison of management perceptions and human resource practices. Journal of World Business, 49(2), 225-235.

D’Abate, C. P., Eddy, E. R., \& Tannenbaum, S. I. (2003). What's in a name? A literaturebased approach to understanding mentoring, coaching, and other constructs that describe developmental interactions. Human Resource Development Review, 2(4), 360-384

Davidson, M. C., McPhail, R., \& Barry, S. (2011). Hospitality HRM: past, present and the future. International Journal of Contemporary Hospitality Management, 23(4), 498-516.

Eby, L. T., Butts, M. M., Durley, J., \& Ragins, B. R. (2010). Are bad experiences stronger than good ones in mentoring relationships? Evidence from the protégé and mentor perspective. Journal of Vocational Behavior,77(1), 81-92.

Garvey, B., Stokes, P., \& Megginson, D. (2014). Coaching and mentoring: Theory and practice. Sage.

Gannon, J. M., \& Maher, A. (2012). Developing tomorrow's talent: the case of an undergraduate mentoring programme. Education + Training, 54(6), 440-455.

Grima, F., Paillé, P., H. Mejia, J., \& Prud'homme, L. (2014). Exploring the benefits of mentoring activities for the mentor. Career Development International, 19(4), 469-490.

Gutner, T., (2009), Finding Anchors in the Storm: Mentors, The Wall Street Journal, Business, accessed 22.06.2014

Harvey, M., McIntyre, N., Thompson Heames, J., \& Moeller, M. (2009). Mentoring global female managers in the global marketplace: traditional, reverse, and reciprocal mentoring. The International Journal of Human Resource Management, 20(6), 1344-1361. 
Hu, C., Wang, S., Yang, C. C., \& Wu, T. Y. (2014). When mentors feel supported: Relationships with mentoring functions and protégés' perceived organizational support. Journal of Organizational Behavior, 35(1), 22-37.

Ibarra, H., Carter, N. M., Silva, C., (2010), Why Men Still Get More Promotions Than Women, Harvard Business Review, accessed 01.06.2014

Inzer, L. D., \& Crawford, C. B. (2005). A review of formal and informal mentoring: processes, problems, and design. Journal of Leadership Education, 4(1), 31-50.

Joo, B.-K., Sushko, J. S., McLean, G. N., (2012), Multiple Faces of Coaching: Manager-ascoach, Executive Coaching, and Formal Mentoring, Organization Development Journal, 30(1), 19-38.

Kim, S. S., Im, J., \& Hwang, J. (2015). The effects of mentoring on role stress, job attitude, and turnover intention in the hotel industry. International Journal of Hospitality Management, 48, 68-82.

Klasen, N., \& Clutterbuck, D. (2012). Implementing mentoring schemes. Routledge.

Kong, H., Wang, S., \& Fu, X. (2015). Meeting career expectation: can it enhance job satisfaction of Generation Y?. International Journal of Contemporary Hospitality Management, 27(1), 147-168.

Kusluvan, S., Kusluvan, Z., Ilhan, I., \& Buyruk, L. (2010). The human dimension a review of human resources management issues in the tourism and hospitality industry. Cornell Hospitality Quarterly, 51(2), 171-214.

Lankau, M. J., \& Chung, B. G. (1998). Mentoring for line-level employees. Cornell Hotel and Restaurant Administration Quarterly, 39(6), 14-19.

Lee, K. J. (2016). Sense of calling and career satisfaction of hotel frontline employees: mediation through knowledge sharing with organizational members. International Journal of Contemporary Hospitality Management, 28(2).

Megginson, D., Clutterbuck, D., Garvey, B., Stokes, P., Garrett-Harris, R., (2006), Mentoring in Action - a practical guide, $2^{\text {nd }}$ edition, London: Kogan Page Limited

Meister, J. C., \& Willyerd, K. (2010). Mentoring millennials. Harvard business Review, 88(5), 68-72.

Meliou, E., \& Maroudas, L. (2011). Career development in the hospitality industry in Greece: Implications for human resource practices. Journal of Human Resources in Hospitality \& Tourism, 10(2), 218-233.

Murrell, A. J., Blake-Beard, S., Porter, D. M., \& Perkins-Williamson, A. (2009). Interorganizational formal mentoring: Breaking the concrete ceiling sometimes requires support from the outside. Human Resource Management, 47(2), 275-294.

Murphy, W. (2012). Reverse mentoring at work: Fostering cross-generational learning and developing millennial leaders. Human Resource Management, 51(4), 549-573.

Parise, M. R., \& Forret, M. L. (2008). Formal mentoring programs: The relationship of program design and support to mentors' perceptions of benefits and costs. Journal of Vocational Behavior, 72(2), 225-240. 
Ragins, B. R., \& Kram, K. E. (2007). The handbook of mentoring at work: Theory, research, and practice. Sage Publications.

Ragins, B. R., \& Kram, K. E. (2007). The roots and meaning of mentoring. Chapter 1, The handbook of mentoring at work: Theory, research, and practice, pages 3-15.

Rekha, K. N., \& Ganesh, M. P. (2012). Do mentors learn by mentoring others?. International Journal of Mentoring and Coaching in Education, 1(3), 205-217.

Rock, A. D., \& Garavan, T. N. (2006). Reconceptualizing developmental relationships. Human Resource Development Review, 5(3), 330-354.

Rutherford, D. G., \& Wiegenstein, J. (1985). The mentoring process in hotel general managers' careers. Cornell Hotel and Restaurant Administration Quarterly, 25(4), 16-25.

Rutherford, D.G. (1984) Mentoring hospitality managers, Cornell Hotel and Restaurant Administration Quarterly, 25(1), 16-19.

Schutt, R. K., (2012), Investigating the Social World, The Process and Practice of Research, 7th ed., Sage Publications

Simmonds, D., \& Zammit Lupi, A. M. (2010). The matching process in e-mentoring: a case study in luxury hotels. Journal of European Industrial Training, 34(4), 300-316.

Young, A. M., Cady, S., Foxon, M. J., (2006), Demystifying Gender Differences in Mentoring: Theoretical Perspectives and Challenges for Future Research on Gender and Mentoring, Human Resource Development Review, 5(2). 148-175

Zachary, L. J., (2005), Creating a Mentoring Culture: The Organization's Guide, $1^{\text {st }}$ ed., San Francisco, CA: Jossey-Bass, A Wiley Imprint

Zagenczyk, T. J., Gibney, R., Kiewitz, C., \& Restubog, S. L. D. (2009). Mentors, supervisors and role models: do they reduce the effects of psychological contract breach?. Human Resource Management Journal, 19(3), 237-259.

Zey, M. G., (2002), The Mentor Connection, Strategic Alliances in Corporate Life, 6th ed., Transaction Publishers: New Jersey 